\title{
Pesquisa baseada em design: reflexōes a partir de uma situação-problema envolvendo o teorema de pitágoras
}

\author{
Charles Bruno da Silva Melo*, Glaucia Cabral Moraes**, Aline Grohe Schirmer Pigatto**, \\ Eleni Bisognin ${ }^{\star \star \star \star}$
}

\section{Resumo}

O presente trabalho teve por objetivo analisar a eficácia de um artefato pedagógico, nesse caso, uma situação-problema sobre o Teorema de Pitágoras em uma turma do $9^{\circ}$ ano do Ensino Fundamental a partir das etapas propostas por Reeves (2000) para a Pesquisa Baseada em Design (PBD). A pesquisa envolveu um grupo de quatro professores de Matemática e uma turma de $9^{\circ}$ ano composta por 30 alunos de uma escola privada de Santa Cruz do Sul/RS. O estudo se desenvolveu a partir de uma revisão teórica sobre a PBD, bem como foi estrutura nas quatro fases: descrição do problema educativo, descrição do desenvolvimento do artefato pedagógico a partir de uma teoria norteadora, descrição da intervenção pedagógica e descrição de princípios de design. De natureza qualitativa, teve como instrumentos de coleta de dados: a observação participante, durante o desenvolvimento das atividades realizadas pelos alunos no laboratório de informática, e o diário de campo, do pesquisador e do professor titular da turma. Os resultados demonstram que é necessário um envolvimento coletivo dos professores para um planejamento efetivo, assim como objetividade no trabalho docente. Igualmente, deve-se fazer o planejamento do tempo para as atividades que serão desenvolvidas em sala de aula com a exploração do artefato, para proporcionar um maior aproveitamento educacional. Em relação à aplicação do artefato, mesmo sendo necessários alguns ajustes, pode-se afirmar que a situação-problema se configurou como um bom artefato pedagógico, visto que promoveu um envolvimento dos alunos durante toda atividade, proporcionou o uso do software GeoGebra como uma ferramenta pedagógica e permitiu que os estudantes pudessem discutir e refletir de modo coletivo sobre o conteúdo.

Palavras-chave: Pesquisa Baseada em Design. Situação-problema. Teorema de Pitágoras. Ensino de Matemática.

* Doutorando do Programa de Pós-Graduação em Ensino de Ciências e Matemática da Universidade Franciscana (UFN) e professor na Educação Básica. Brasil. E-mail: xarlesdemelo@yahoo.com.br

* Docente da Universidade de Santa Cruz do Sul (UNISC). Brasil. E-mail:glaucia_moraes@sicredi.com.br. Docente do Programa de Pós-Graduação em Ensino de Ciências e Matemática da Universidade Franciscana (UFN). Brasil. E-mail: agspigatto@gmail.com

**** Docente do Programa de Pós-Graduação em Ensino de Ciências e Matemática da Universidade Franciscana (UFN). Brasil. E-mail: eleni.bisognin@gmail.com

Recebido em: 16/03/2020 - Aceito em: 28/12/2020

https://doi.org/ 10.5335/rbecm.v4i1.10729

http://creativecommons.org/licenses/by-nc-nd/4.0 


\section{Introdução}

A partir da vivência profissional ao longo dos anos, nota-se que existe certa dificuldade dos alunos em acompanhar e desenvolver conexões entre representações algébricas e geométricas feitas em aula, em especial, no processo de ensino e aprendizagem envolvendo o Teorema de Pitágoras. Essa ausência de compreensão pode ser oriunda de diversos fatores, dentre eles, a falta da exploração de diferentes formas de representações para um mesmo objeto matemático como evidenciado nos trabalhos de Bastian (2000) e Mottin (2004).

Para que ocorra a transição entre as representações, é necessário que seja explorada a visualização, definida por Leivas (2009) como "um processo de formar imagens mentais, com a finalidade de construir e comunicar determinado conceito matemático, com vistas a auxiliar na resolução de problemas analíticos ou geométricos." (p. 22). Partindo dessa ideia é essencial uma reflexão sobre como ensinar esse objeto de conhecimento. Por isso, adotou-se a Pesquisa Baseada em Design - PBD como uma alternativa pedagógica para esse processo.

Conforme Kelly (2003), a ideia de design está fortemente relacionada ao desenvolvimento de um produto/artefato pedagógico. A PBD não busca somente desenvolver e testar intervenções, mas incorporar e refletir relações entre teoria, artefato pedagógico desenvolvido e a prática, para dessa forma, contribuir para o cenário educacional.

Diante deste contexto, neste trabalho discutimos a abordagem da PBD no âmbito de uma pesquisa cujo objetivo é analisar a eficácia de uma situação-problema sobre o Teorema de Pitágoras em uma turma do $9^{\circ}$ ano do Ensino Fundamental a partir das fases da PBD propostas por Reeves (2000).

\section{Orientações teóricas}

De acordo com Ramos (2010):

Pesquisa Baseada em Design refere-se a abordagens que assumem como compromisso aliar pesquisa e desenvolvimento de intervenções pedagógicas em contextos reais de aprendizagem, com o objetivo tanto de promover a melhoria das práticas educativas quanto de produzir conhecimentos sobre o processo ensino-aprendizagem (p. 21). 
A PBD gerencia todo o processo, desde a ideia de inovação/criação até a implementação em um ambiente real. Portanto, é fundamental que haja uma apreciação de todo o processo e não apenas somente do produto final, pois os resultados dessa análise deverão ser incorporados na própria metodologia visando seu aperfeiçoamento. Por isso, uma importante característica da PBD é sua estrutura cíclica, já que o que é aprendido de um primeiro design deve ser utilizado nos próximos. Collins, Joseph e Bielaczyc (2004) comparam a PBD como um processo em indústrias de carro. Segundo eles,

[...] experimentos de design foram desenvolvidos como uma forma de realizar uma pesquisa formativa para testar e aperfeiçoar projetos educacionais com base em princípios teóricos derivados de prévia pesquisa. Esta abordagem de refinamento progressivo em 'design' envolve a colocação de uma primeira versão de um projeto para o mundo ver como ele funciona. Em seguida, o projeto é constantemente revisado baseado na experiência, até que todos os erros sejam trabalhados. O refinamento progressivo na indústria de carros foi lançado pelos japoneses, que ao contrário dos fabricantes americanos de automóveis, atualizam seus projetos com frequência, ao invés de esperar anos por um modelo de transição para aperfeiçoar projetos passados. A abordagem é também a base do estudo das aulas japonesas, onde grupos de professores se reúnem para aperfeiçoar suas práticas de ensino. (COLLINS, JOSEPH E BIELACZYC, 2004, p.18).

Ainda, conforme Ramos e Struchiner (2010) a PBD tem o foco em problemas educativos tidos como complexos no contexto dos processos de ensino e de aprendizagem a partir de uma abordagem centrada na interação e colaboração entre pesquisadores e demais sujeitos envolvidos nas atividades pedagógicas; como é o caso de professores e alunos.

Outros autores também têm se empenhado em discutir e estabelecer orientações teóricas e metodológicas para demarcar a utilização da PBD na pesquisa e desenvolvimento de ambientes de aprendizagem mediados pelas TICs (SEETO e HERRINGTON, 2006; REEVES, 2000).

Reeves (2000) destaca que existem quatro fases para melhor compreender como funciona a Pesquisa Baseada em Design (Figura 1). 
Figura 1: fases da Pesquisa Baseada em Design conforme Reeves (2000).

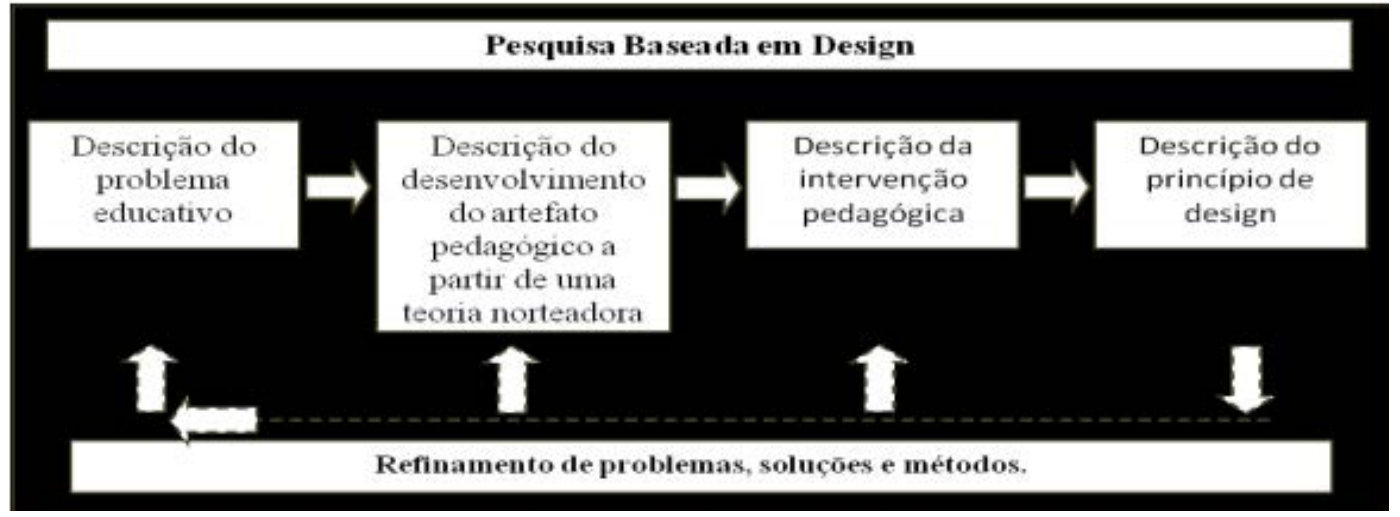

Pode-se compreender esse processo com base em algumas características, dentre as quais destacamos: I) descrição do problema educativo: trata da análise do problema educativo, planejamento e delineamento para estruturação da pesquisa; II) descrição do desenvolvimento do artefato pedagógico a partir de uma teoria norteadora: refere-se ao desenvolvimento do artefato pedagógico, para tanto se faz necessária uma teoria norteadora; III) descrição da intervenção pedagógica: necessária para compreender e avaliar como o artefato pedagógico, nesse caso, como a situação-problema contribui para solução do problema educativo e IV) descrição de princípios de design: aponta à análise retrospectiva para produzir princípios de design.

Todo esse processo é documentado e avaliado, os conhecimentos originados por meio dessa avaliação permitem que se reflita sobre o processo e, com base nessa reflexão, possa se projetar e planejar novas ações. Essas características sinalizam os problemas pedagógicos, as teorias norteadoras e as intervenções como elementos-chave do processo da PBD, configurando, portanto, o foco da nossa análise.

Cabe ressaltar também, que a PBD tem caráter intervencionista, já que promove uma ligação entre teórica e prática, buscando contribuir nas duas dimensões. Van den Akker (1999) enfatiza que a inter-relação entre a teoria e a prática é complexa e dinâmica e que a aplicação direta da teoria muitas vezes não é suficiente para resolver alguns tipos de problemas relacionados à prática. Ele ainda afirma que "sem o envolvimento cooperativo de pesquisadores e profissionais não é possível ganhar uma clareza sobre os problemas advindos da implementação e gerar medidas efetivas para reduzi-los" (Van den Akker, 1999, p.9). 


\section{PBD por meio de uma situação-problema envolvendo o Teorema de Pitágoras}

Em relação à pesquisa ora apresentada, a primeira fase foi utilizada para estabelecer o objetivo voltado ao trabalho do professor e o uso da situação-problema em sala de aula. A segunda fase abrangeu a delimitação do artefato, nesse caso estabelecido como uma situação-problema envolvendo o Teorema de Pitágoras e da teoria norteadora, enquanto a terceira fase consistiu da intervenção pedagógica. A quarta fase aponta à análise retrospectiva da metodologia.

\section{Fase I: descrição do problema educativo}

A partir da vivência profissional, percebeu-se que os alunos apresentam dificuldades na compreensão do Teorema de Pitágoras, principalmente na conexão entre a representação geométrica, que o define, aliado a uma valorização apenas da representação algébrica, que por muitas vezes é utilizada sem a devida relação conceitual.

Sendo assim, um grupo de quatro professores de Matemática de uma escola particular em Santa Cruz do Sul/RS reuniram-se para planejar e traçar estratégias que pudessem superar esse cenário. Durante os encontros semanais, foi definido que o artefato pedagógico deveria envolver o uso de algum software de geometria dinâmica, pois era necessário que os alunos pudessem manipular e visualizar a relação do Teorema de Pitágoras.

De acordo com Cruz (2005), a geometria dinâmica é aquela que permite sua exploração por meio do movimento de figuras, na tela de um computador, cujas características estabelecem condições para que o usuário (aluno) manuseie seus componentes e realize conjecturas, atendendo aos requisitos necessários para que se observem regularidades.

Foi escolhido o software GeoGebra, que é um programa livre de geometria dinâmica, adequado para a análise gráfica, pois nele podem-se explorar conceitos geométricos e algébricos. Outros fatores importantes na escolha desse software foram: a facilidade de sua interface, pois os comandos são apresentados em linguagem simples e de fácil entendimento, além dos professores já terem utilizado em turmas dos anos anteriores, propiciando assim, que os alunos já tenham um domínio maior na manipulação. 
Segundo Vieira (2010, p. 59), “o GeoGebra permite ao usuário manipular os objetos, de forma conveniente, gerando discussões a respeito do que está sendo estudado durante o desenvolvimento das atividades de geometria".

Da mesma forma, deveria ser desenvolvida e utilizada uma situação-problema que pudesse ser real, pois possibilita desenvolver uma gama de habilidades e competências relacionadas ao conhecimento matemático. Para Pozo (1998) um dos modos mais acessíveis para levar os alunos a aprender a aprender é a solução de situações-problema, no sentido de tornar um hábito que os alunos possam encontrar por si mesmos respostas às perguntas que os inquietam. Portanto, a solução de problemas consiste na apresentação de situações que exijam dos alunos uma atitude ativa e um esforço para buscar suas próprias respostas, seu próprio conhecimento.

Definido que o artefato pedagógico seria uma situação-problema envolvendo o uso do GeoGebra, foi necessário analisar em que ano do Ensino Fundamental deveria ser aplicado. Conforme a Base Nacional Comum Curricular (BRASIL, 2017) o Teorema de Pitágoras deve ser trabalho nas turmas de $9^{\circ}$ ano de modo a desenvolver as habilidades de: demonstrar relações métricas do triângulo retângulo, resolver e elaborar problemas de aplicação do Teorema de Pitágoras. Portanto, o artefato pedagógico foi direcionado para ser utilizada com alunos do $9^{\circ}$ ano que já possuem noções básicas envolvendo o triângulo retângulo, bem como conhecimentos mínimos relacionados ao uso do software GeoGebra.

\section{Fase II: desenvolvimento do artefato e teoria norteadora}

O artefato é uma situação-problema denominada "Pedro e Pitágoras" sendo criada com características de uma situação real a partir do método de estudo de caso (Figura 2). Segundo Sá e Queiroz (2010), casos são narrativas sobre dilemas, vivenciados por pessoas que necessitam tomar decisões a respeito de determinados assuntos. A familiarização com o contexto do caso e com os seus personagens acaba por impulsionar os estudantes na busca de escolhas, e posterior tomada de decisão, necessária para a sua resolução. 
Figura 2: Situação-problema utilizada como artefato pedagógico.

"Pedro e Pitágoras"
Pedro sempre morou e estudou em Candelária, onde concluiu o Ensino Médio juntamente com alguns
amigos de infância. Depois de tantos anos estudando juntos, finalmente a separação foi inevitável. Pedro
prestou vestibular para Matemática na UFSM e Jorge para Letras, na mesma universidade. Fernando, Sinara,
Diana e Marcia optaram por Arquitetura na UNISC. Ao visitar a família no feriado, Pedro tomou
conhecimento de uma situação estranha que ocorria por lá. Logo ao amanhecer, ao tomar café, seus pais, Seu
Charles e Dona Marcia, lhe contaram o que estava acontecendo.
- Filho, estão construindo uma praça na cidade, mas ela é diferente. Vai ter o formato de Pitágoras.
Não, o formato da representação do matemático, mas da comprovação geométrica do seu teorema. Porém, os
arquitetos da prefeitura não conseguem definir que figuras geométricas utilizam.
- Pai, eu posso ajudar! E meus amigos que estudam arquitetura na UNISC também.
Você é um dos amigos de infância de Pedro, e terá que ajudá-lo a resolver o problema da construção
da praça de Pitágoras. Por isso, temos que pensar e solucionar as seguintes situações:

Além dessa estrutura, a situação-problema foi construída também levando em conta a definição de um bom problema proposta por Dante (1998). O autor ressalta que um bom problema deve: ser desafiador para o aluno, real, interessante, ser o elemento de um problema realmente desconhecido; não consistir na aplicação evidente e direta de uma ou mais operações aritméticas e ter um nível adequado de dificuldade.

\section{Fase III: descrição da intervenção pedagógica}

A vivência da situação-problema foi realizada em novembro de 2019 em uma escola privada de Santa Cruz do Sul/RS e contou com a participação de uma turma de $9^{\circ}$ ano do Ensino Fundamental com 30 alunos no tempo de 2h/aula de 45 minutos (Figura 3). 
Figura 3: Turma resolvendo a situação-problema.

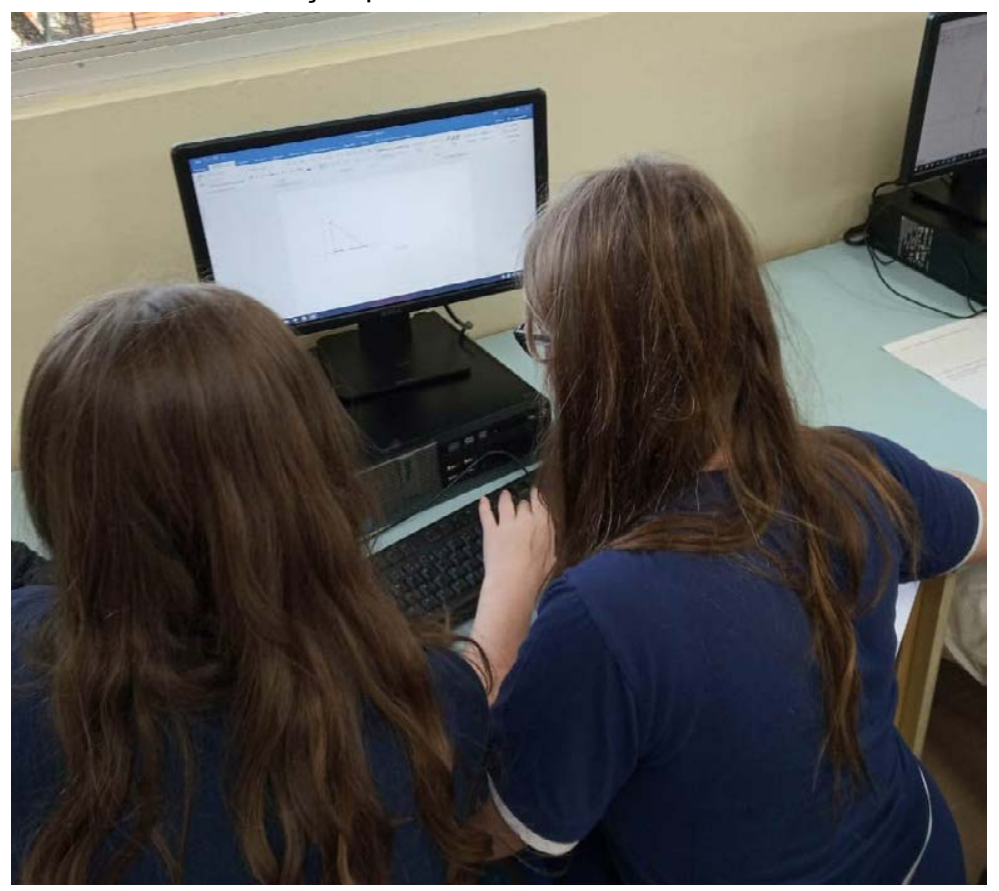

A atividade foi acompanhada por dois professores que utilizaram como instrumentos de coleta de dados: o diário de campo e a observação participante.

De acordo com Severino (2007, p. 125), observação “é todo procedimento que permite acesso aos fenômenos estudados. É etapa imprescindível em qualquer tipo ou modalidade de pesquisa”. Nessa pesquisa, a observação participante garantiu um conjunto de registros no diário de campo, ou seja, um variado número de informações fundamentais para o trabalho. Justifica-se a escolha desse instrumento porque proporciona aos professores uma visão detalhada de todo o processo.

Por meio do diário de campo, Fiorentini e Lorenzato (2006, p.119) afirmam que “o pesquisador registra observações de fenômenos, faz descrições de pessoas e cenários, descreve episódios ou retrata diálogos”.

O diário de campo é uma ferramenta na qual, conforme Minayo (1993, p.100):

[...] constam todas as informações que não sejam o registro das atividades formais. Ou seja, observações sobre conversas informais, comportamentos, cerimoniais, festas, instituições, gestos, expressões que digam respeito ao tema da pesquisa. Fala, comportamento, hábitos, usos, costumes, celebrações e instituições compõem o quadro das representações sociais. 
Utilizando esses dois instrumentos, foram analisadas, mais especificamente: as dificuldades e facilidades no processo, as diferentes soluções para um mesmo questionamento e a participação dos alunos durante a aplicação do artefato, bem como a descrição de toda a atividade em sala de aula.

Inicialmente, os alunos foram conduzidos ao laboratório de informática da escola e informados que poderiam formar pequenos grupos para realizar a atividade. Em seguida, a professora titular propôs a situação-problema aos estudantes, avisando a necessidade e a importância dos registros das estratégias escolhidas, assim como a utilização do GeoGebra para auxiliar na tomada de decisões.

Durante essa organização, muitos alunos já estavam com a janela do software aberta, porém estavam receosos em iniciar a tarefa. Nesse caso, foi necessário que a professora explicasse novamente, só que dessa vez, individualmente aos grupos.

O primeiro questionamento destinado aos estudantes, após a leitura da situação-problema, foi o que é o Teorema de Pitágoras. Para auxiliar na resposta, foi sugerido que eles realizassem uma pesquisa de modo rápido. Nessa etapa, a maioria dos grupos apenas registrou a representação algébrica do teorema, conforme ilustra a Figura 4.

Figura 4: Registro ao primeiro questionamento.

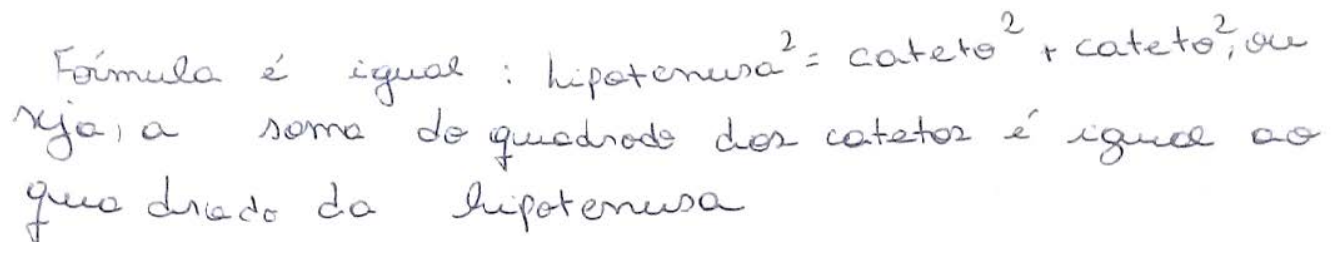

Na sequência, a professora informou que: "O Teorema de Pitágoras é válido para um triângulo retângulo. Portanto a base da praça deve ser essa figura geométrica. Utilizando o GeoGebra, como é possivel construir um triângulo retângulo? Ajude nessa construção! Você não pode utilizar a ferramenta polígono, deve pensar nos elementos que caracterizam um triângulo retângulo." Grande parte dos estudantes optaram pela utilização de retas perpendiculares para a construção do triângulo retângulo, evidenciando que eles identificam a principal característica de um triângulo retângulo, como também o conceito de reta perpendicular (Figura 5). 
Figura 5: Registro da construção do triângulo retângulo.

Usando a ferramenta de retas perpendiculares, traçamos três retas, pela qual formaram um truânguls retângulo, então utelizamos a ferramenta "ângulos" para comproviar s ângulo de $90^{\circ}$

Posteriormente, os alunos receberam a informação: "Durante a conversa com os amigos, Pedro afirma: "Se eu construir quadrados sobre a hipotenusa e sobre os catetos posso comprovar o Teorema de Pitágoras. Esse poderá ser o formato da praça." Essa afirmação está correta? Por quê? Faça a construção no GeoGebra e verifique! Não esqueça de registar e explicar a estratégia." Nesse caso, a maioria dos alunos afirmou que estava correto o raciocínio, justificando que a soma das áreas dos quadrados construídos com lados iguais aos catetos é igual a área do quadrado cujo lado é a hipotenusa, conforme Figura 6.

Figura 6: Registro justificando o terceiro questionamento.

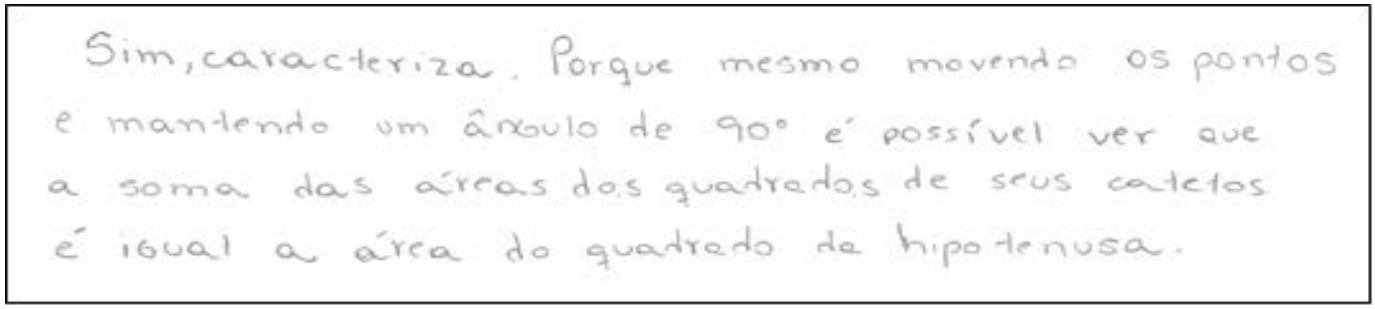

Novamente foi lançado um questionamento. Fernando, durante a atividade anterior fez uma observação pertinente. " $E$ se ao invés de construirmos quadrados sobre os catetos e a hipotenusa, construíssemos outros polígonos regulares como triângulos, pentágonos ou hexágonos, existe uma relação entre as áreas dos polígonos construídos sobre os catetos e a hipotenusa? Ainda teríamos a relação do Teorema de Pitágoras?". Essa pergunta proporcionou muitas discussões entre os alunos, de modo que a professora pode mediar esse processo entre os grupos.

Alguns alunos já tinham estudados o Teorema de Pitágoras e outros não, muitos já tinham visto a representação geométrica do teorema utilizando os quadrados, mas não sabiam o porquê. Da mesma forma, eles puderam observar que a relação 
entre a soma das áreas dos polígonos construídos sobre os catetos é igual à área do polígono construído sobre a hipotenusa se mantém para outros polígonos regulares, porém não caracteriza o teorema de Pitágoras. Essa constatação, foi percebida apenas por um grupo (Figura7). A medida que os alunos iam realizando as construções no GeoGebra e constatando a relação da soma das áreas, surgiam cada vez mais dúvidas com relação ao teorema.

Figura 7: Registro do grupo que respondeu corretamente.

$$
\text { A relocpó das oréas se mantí, pais a sama }
$$

dos areas dos figuras dos cotetos é igud a oréa da figura sobre a heotimusa. Nóo caractieriza o teorena de Pitiogires, pois peganda a medela des cotetos e elevoudo Do quadrode nāo dá o vala. Sór a ariea do quadra. do é hado as quadrodo

Na questão seguinte, os alunos receberam a informação: "Diana foi além. Pensou em construir um chafariz com a representação geométrica do teorema de Pitágoras utilizando o volume. Para isso, sugeriu projetar alturas sobre as figuras planas construídas sobre os catetos e a hipotenusa. Nessa situação, a relação do teorema poderia ser utilizada para o volume? Poderia ser uma aplicação do teorema de Pitágoras?”. Nesse questionamento, todos os alunos afirmaram que não poderia ser utilizado o Teorema de Pitágoras para o volume. Foram utilizadas como justificativas: "as medidas dos catetos e hipotenusas são elevadas ao quadrado e não ao cubo" e "o teorema envolve figuras bidimensionais ou planas e não tridimensionais".

Finalizando a exploração do artefato, foi questionado: "A partir das situações vivenciadas juntamente com Pedro e seus amigos, qual deve ser o formato da praça que respeita a representação do teorema de Pitágoras e, portanto, pode ser enviado para a prefeitura?”. Os alunos receberam os possíveis formatos para a praça, conforme Figura 8. 
Figura 8: Possíveis formatos para a praça.

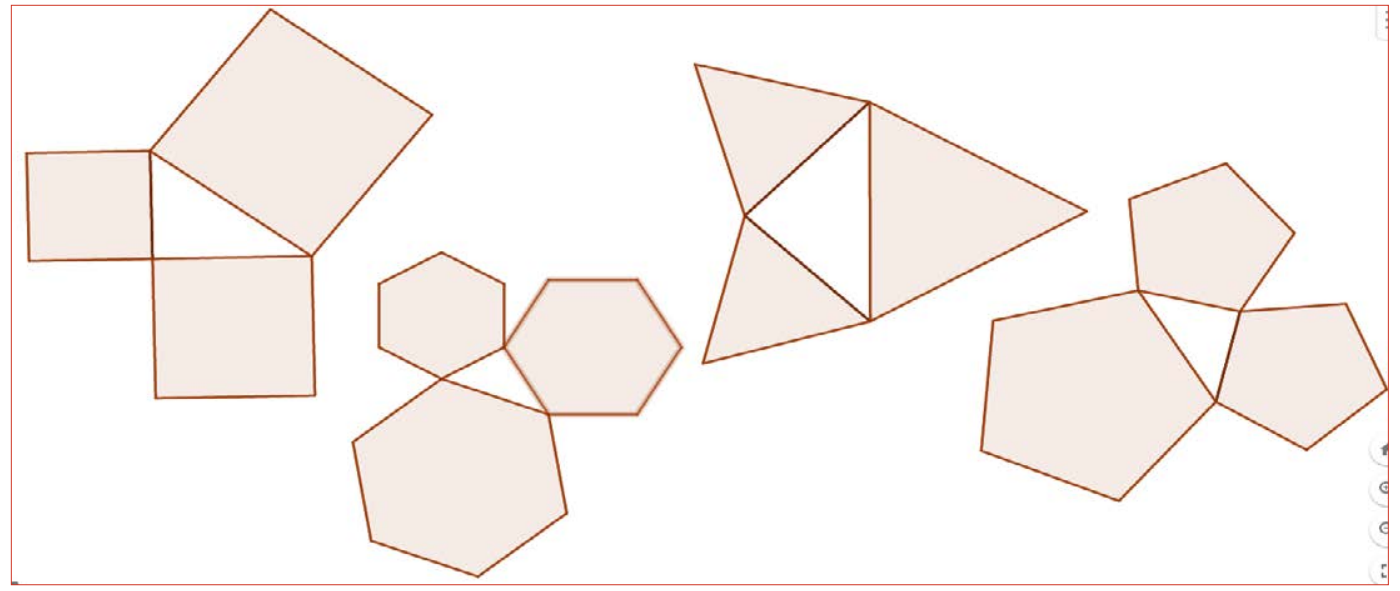

Essa questão tinha por intuito que os alunos pudessem identificar a representação geométrica para a expressão algébrica que descreveram na primeira atividade, por sua vez, comprovariam o Teorema de Pitágoras. A maioria dos estudantes optou pela representação envolvendo quadrados sobre os catetos e hipotenusa, com a justificativa de que para se calcular a área do quadrado deve-se elevar ao quadrado a medida do lado, porém, dez alunos afirmaram que poderia ser qualquer formato, já que em todos a soma das áreas dos polígonos sobre os catetos era igual à área do polígono construído sobre a hipotenusa.

\section{Fase IV: analisando a experiência}

Essa fase consiste na análise das fases anteriores, com o intuito de identificar pontos positivos e negativos, e a partir dessa análise, modificar o que for necessário para poder voltar ao campo de pesquisa e aplicar novamente o artefato pedagógico.

Na primeira fase, podem ser apontados como pontos positivos o comprometimento do grupo de professores em se reunir semanalmente, dentro das reuniões já previstas no calendário escolar, bem como a objetividade em definir um problema comum e que estratégias utilizar.

No desenvolvimento do artefato, ocorreram alguns equívocos em relação ao planejamento do tempo para aplicação da atividade. A situação-problema deveria ser resolvida em mais períodos de aula, pois os estudantes poderiam discutir e 
argumentar melhor suas estratégias. Do mesmo modo, seria necessário revisar em que momento o artefato deveria ser utilizado: para introduzir o Teorema de Pitágoras para os alunos que ainda não conheciam esse resultado. Utilizamos o artefato em um momento em que a turma já havia iniciado o estudo, porém não finalizado, promovendo ainda mais discussões acerca do conteúdo.

Durante a intervenção pedagógica, pode-se constatar que a turma se envolveu bastante na atividade. Os alunos pontuaram que gostaram de utilizar o GeGebra, da mesma forma questionaram que o tempo foi curto; gostariam de ter mais tempo para realizar as atividades e um número maior de construções no software. Além disso, a proposta possibilitou que os estudantes tivessem momentos para discutir e refletir de modo coletivo o conteúdo em estudo.

Essas etapas serão revistas para uma nova utilização da situação-problema em sala de aula, ajustando os itens mencionados promovendo a forma cíclica da PBD.

\section{Considerações Finais}

Após o desenvolvimento da investigação baseada nas fases da PBD proposta por Reeves (2000), foi possível constatar que é necessário um envolvimento coletivo dos professores para um planejamento efetivo, assim como objetividade no trabalho docente.

Igualmente, teve-se ter um cuidado com o planejamento do tempo para as atividades que serão desenvolvidas em sala de aula e o foco na implementação do artefato. Desse modo pode-se estabelecer com segurança o momento adequado para a utilização dele, proporcionando um maior aproveitamento educacional. Como sugestão, poderia nesse caso, testar o artefato com o grupo de professores que o elaborou, antes de sua aplicação em sala de aula, possibilitando a verificação de possíveis falhas no processo.

Em relação a aplicação do artefato, mesmo sendo necessário alguns ajustes, pode-se afirmar que a situação-problema se configurou como um bom artefato pedagógico, visto que promoveu um envolvimento dos alunos durante toda atividade, proporcionou o uso do software GeoGebra como uma ferramenta pedagógica importante na visualização de representações geométricas e tomada de decisões. Permitiu que os estudantes pudessem discutir e refletir de modo coletivo sobre o conteúdo, e desse modo, aprenderem em ação, ou seja, foram sujeitos ativos no processo de construção do próprio conhecimento, além de ser uma proposta diferente daquela que vinha sendo utilizada em anos anteriores. 


\section{Agradecimento}

O presente trabalho foi realizado com apoio da Coordenação de Aperfeiçoamento de Pessoal de Nível Superior - Brasil (CAPES) Código de Financiamento 001.

\section{Design based research: reflections from a problem-situation involving the pythagorean theorem}

\section{Abstract}

This activity had the purpose to analyze the efficiency of a pedagogical artifact, in this case, a problem-situation about the Pythagorean theorem applied with a 9th grade basic school class starting from the phases presented by Reeves (2000) to the Design Based Research (DBR). The research involved a group of four math teachers and a 30 students 9th grade class of a private school in Santa Cruz do Sul/RS. The study was developed starting from a theoretical review about DBR, as well as it was structured in four phases: description of the educational problem, of the pedagogical artifact development from a guiding theory, of the pedagogical intervention and the description of the design principles. In a qualitative way, the following data collection instruments were used: participant observation, during the development of the activities accomplished by the students in the computer lab, and the field journal, from the researcher and class teacher. The results show that it's necessary to exist a collective involvement of teachers in order to get a effective planing, just like objectivity in teaching work. Equally, the time of the activities, which are going to be developed in the classroom with the artifact exploration, must be planned, in order to provide a bigger educational achievement. Regarding the artifact application, even with the requirement of some adjustments, it can be affirmed that the situation-problem was ellected as a good pedagogical artifact, once it promoted the students envolvement during all the activity, provided the usage of GeoGebra software as a pedagogical tool and also allowed the students to discuss and reflect together about the topic.

Keywords: Design Based Research. Problem situation. Pythagorean Theorem. Mathematics Teaching.

\section{Referências}

BRASIL. Base Nacional Comum Curricular. Brasília: MEC, 2017. Disponível em: http:// basenacionalcomum.mec.gov.br/images/BNC C_20dez_site.pdf. Acesso em: 2 dez. 2019.

BASTIAN, I. V. O teorema de Pitágoras. 2000. Dissertação (Mestrado em Educação) - Programa de Estudos Pós-Graduados em Educação Matemática, Pontifícia Universidade Católica de São Paulo, São Paulo, 2000.

COLLINS, A., JOSEPH, D.; BIELACZYC, K. Design research: Theoretical and methodological issues. Journal of the Learning Sciences, Filadélfia, v. 13, n. 1, p. 15-42, 2004. DOI:10.1207/ s15327809jls1301_2

CRUZ, D. G. A utilização do ambiente dinâmico e interativo na construção de conhecimento distribuído. Dissertação (Mestrado em Educação) - Curso de Pós-Graduação em Educação, Universidade Federal do Paraná, Curitiba, 2005. 
DANTE, L.R. Didática da Resolução de Problemas de Matemática. 2. ed. São Paulo: Ática, 1998. FIORENTINI, D.; LORENZATO, S. Investigações em educação matemática: percursos teóricos e metodológicos. Campinas: Autores Associados, 2006.

KELLY, A. E. Theme issue: the role of design in educacional research. Educational Researcher, v. 32 , n. 1, p. 3-4, 2003.

LEIVAS, J. C. P. Imaginação, Intuição e Visualização: a riqueza de possibilidades da abordagem geométrica no currículo de cursos de licenciatura de matemática. Tese (Doutorado em Educação) - Programa de Pós-graduação em Educação, Universidade Federal do Paraná. Curitiba, 2009.

MINAYO, M. C. de S. O Desafio do Conhecimento: pesquisa qualitativa em saúde. 2. ed. São Paulo: HUCITEC, 1993.

MOTTIN, E. A Utilização de material didático-pedagógico em ateliês de matemática para o estudo de Teorema de Pitágoras. Dissertação (Mestrado em Ciências e Matemática) - Programa de Pós-Graduação em Educação em Ciências e Matemática, Pontifícia Universidade Católica do Rio Grande do Sul, Porto Alegre, 2004.

POZO, J. I. A solução de problemas: aprender a resolver, resolver para aprender. Porto Alegre: Artmed, 1998.

RAMOS, P.; STRUCHINER, M. Desenvolvimento de um ambiente virtual para o ensino da medicina por uma equipe multidisciplinar: fatores que influenciam a análise do problema educativo. Interface, Botucatu, v. 15, n. 36, p. 227-242, 2011. http://dx.doi.org/10.1590/S141432832010005000041.

RAMOS, P. Ambiente Virtual Vivências: análise do processo de desenvolvimento na perspectiva da pesquisa baseada em design. Tese (Doutorado) - Programa de Pós-Graduação em Educação em Ciências e Saúde, Núcleo de Tecnologia Educacional para a Saúde, Universidade Federal do Rio de Janeiro, Rio de Janeiro, 2010.

REEVES, T. C. Enhancing the worth of instructional technology research trough "design experiments" and other developmental research strategies, Annaual meeting of the American Educational research association (AERA). New Orleans, LA, 2000. Disponível em: http://treeves.coe.uga.edu/AERA2000Reeves.pdf. Acesso em: 19 jan. 2020.

SÁ, L.P.; QUEIROZ, S.L. Estudo de casos no ensino de química. Campinas: Átomo, 2010.

SEETO, D.; HERRINGTON, J. Design-based research and the learning designer. Proceed ings of the 23rd annual ascilite conference: Who's learni ng? Whose tec hnology? 2006. Disponível em: https://www.researchgate.net/publication/228664268_Design-based_research_and_the_learning_designer. Acesso em: 22 jan. 2020.

SEVERINO, A. J. Metodologia do trabalho científico. 23. ed. rev. e atual. São Paulo: Cortez, 2007.

VAN DEN AKKER, J. Principles and methods of development research. In: VAN DEN AKKER, J.; NIEVEEN, N.; BRANCH, R. M.; GUSTAFSON, K. L.; PLOMP, T. (Eds.). Design Approaches and Tools in Education and Training. Netherlands: Kluwer Academic Publishers, 1999. p. 1-14.

VIEIRA, C. R. Reinventando a Geometria no Ensino Médio: uma abordagem envolvendo materiais concretos, softwares de geometria dinâmica e a Teoria de Van Hiele. Dissertação (Mestrado Profissional) - Programa de Pós-Graduação em Educação Matemática, Universidade Federal de Ouro Preto, Ouro Preto, 2010. 